\title{
Hospital Administration
}

National Cancer Institute

\section{Source}

National Cancer Institute. Hospital Administration. NCI Thesaurus. Code C15253.

General management of a hospital, or the more specific processes involved in the management of an individual department. 